\title{
Pengendalian Gulma pada Perkebunan Karet (Hevea brasiliensis Muell Arg.) di Gurach Batu Estate, Asahan, Sumatera Utara
}

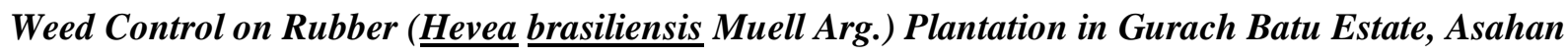 North Sumatera}

\author{
Parid Ridwan Nugraha dan Sofyan Zaman*
}

Departemen Agronomi dan Hortikultura, Fakultas Pertanian, Institut Pertanian Bogor (Bogor Agricultural University), Jl. Meranti, Kampus IPB Darmaga, Bogor 16680, Indonesia Telp. \& Faks.62-251-8629353 e-mail agrohort@apps.ipb.ac.id

*Penulis Korespondensi : sofyanzaman@yahoo.co.id

Disetujui : 30 Oktober 2018 / Published Online 06 Mei 2019

\begin{abstract}
This research activity aims to record the types of weeds that grow under different age of rubber stands plants and how effective control management is. The activity started from February to Mei 2015 in Gurach Batu Estate, Asahan, North Sumatera. Observation of weed vegetation made with the analysis of vegetation in 13 blocks with 13 different planting years to get summed diminance ratio (SDR) and index of similarity. Another observation is the way weed control, along with its effectiveness and efficiency. The dominance weed data were analyzed using analysis of the amount of dominance ratio $(A D R)$, while other observation analyzed description. The results showed that the dominan weed in GBE are Mucuna bracteata, Diplazium asperum, Selaginella deoderleinii, Nephrolepis bisserata. Weed control management is done with manually, chemically and technically method.
\end{abstract}

Keywords: dominan wed, effectiveness, efficiency, herbicides, labour achievments

\begin{abstract}
ABSTRAK
Kegiatan penelitian ini bertujuan untuk mendokumentasikan jenis gulma yang tumbuh di bawah tegakan tanaman karet yang berbeda umur dan bagaimana manajemen pengendalian yang efektif. Kegiatan berlangsung dari Februari - Mei 2015 di Gurach Batu Estate, Asahan, Sumatera Utara. Pengamatan vegetasi gulma dilakukan dengan analisis vegetasi pada 13 blok dengan 13 tahun tanam yang berbeda untuk mendapatkan nisbah jumlah dominan (NJD) dan koefisien komunitas. Pengamatan lain adalah teknik pengendalian gulma, serta efektifitas dan efisisensi pengendaliannya. Data gulma dianalisis menggunakan nisbah jumlah dominan (NJD), sedangkan pengamatan lain dianalisis secara deskriftif. Hasil pengamatan menun jukan bahwa gulma yang dominan di GBE adalah Mucuna bracteata, Diplazium asperum, Selaginella deoderleinii, Nephrolepis bisserata. Manejemen pengendalian gulma dilakukan secara manual, kimiawi dan kultur teknis.
\end{abstract}

Kata kunci: gulma dominan, efektivitas, efisiensi, herbisida, prestasi kerja 


\section{PENDAHULUAN}

Lima negara penghasil karet alam terbesar pada tahun 1993-2013 adalah Thailand, Indonesia, Malaysia, India, dan China (FAO 2014). Indonesia sebagai negara yang memproduksi karet alam mempunyai lahan terluas di dunia. Menurut data BPS tahun 2013, menunjukkan bahwa pada tahun 2012 Indonesia memiliki lahan seluas 3506 juta hektar dengan total produksi 3012 juta ton karet kering.

Potensi lahan yang luas belum dapat digunakan untuk mengoptimalkan produksi karet alam Indonesia. FAO (2012) mencatat Thailand memiliki lahan 2.05 juta hektar dengan total produksi 3.5 juta ton karet kering. Produksi karet alam Thailand mampu menyaingi Indonesia dengan produktivitas yang lebih baik dan menempatkan Thailand sebagai produsen karet alam terbesar dunia. Menurut Damanik et al (2010) potensi lahan produksi karet alam Indonesia belum diimbangi dengan pengelolaan produksi yang memadai.

Meningkatnya hasil produksi perkebunan sering kali melewati berbagai kendala, diantaranya adanya tanaman yang tidak diinginkan yang tumbuh di sekitar tanaman budidaya bahkan menempel pada tanaman itu sendiri atau sering disebut gulma. Kerugian yang disebabkan adanya gulma ini ialah karena terjadinya persaingan dalam perebutan hara serta cahaya matahari antara tanaman budidaya dengan gulma (Setiawan dan Andoko 2005).

Untuk tumbuh kembang suatu tanaman dibutuhkan suatu lingkungan tumbuh yang baik. Lingkungan tumbuh tanaman ini adalah kebutuhan atau persyaratan tumbuh tanaman agar tanaman memiliki pertumbuhan, daya hidup serta daya produksi yang normal. Kebutuhan akan lingkungan tumbuh tersebut untuk setiap tanaman berbeda-beda, akan tetapi unsur-unsur aktifitas untuk tumbuh dan berkembang yang dibutuhkan untuk setiap tanaman adalah sama. Unsur-unsur tersebut adalah cahaya, suhu, air, udara dan hara tanaman (Turrini 2012).

Manusia membudidayakan tanaman untuk memenuhi kebutuhan hidupnya, maka dari itu manusia berusaha untuk mengendalikannya. Agar gulma ini tidak menimbulkan kerugian yang terlalu signifikan terhadap tanaman budidaya maka perlu melakukan pengelolaan.

Gulma yang dikenal merupakan tumbuhan pengganggu selain memiliki sifat negatif juga memiliki sifat positif atau menguntungka. Jika dilihat dari sifat tersebut maka pengelolaan gulma selalu menimbang ke dalam dua terminologi, yaitu pengendalian atau pemberantasan.
Pengendalian gulma adalah tindakan pengelolaan gulma dengan cara menekan keberadaan atau populasi gulma hingga tingkat yang tidak merugikan secara ekonomis. Istilah ke dua yaitu pemberantaan gulma ialah upaya untuk menghilangkan atau memusnahkan bagiannya dari suatau areal (Sembodo 2010).

Kegiatan penelitian ini secara khusus bertujuan untuk menambah pemahaman dan keterampilan dalam pemeliharaan budidaya tanaman karet khususnya dalam hal pengendalian gulma yang meliputi identifikasi jenis gulma dominan, teknik pengendalian gulma, efektivitas dan efisiensi, dan penggunaan alat pelindung diri.

\section{BAHAN DAN METODE}

Kegiatan penelitian dilaksanakan di Kebun Gurach Batu Estate, Asahan, Sumatera Utara pada Februari 2015 - Juni 2015. Data penelitian menggunakan data primer dan sekunder. Data primer yang diamati yaitu nisbah jumlah dominan (NJD), teknik pengendalian gulma, kalibrasi alat semprot, prestasi kerja, penggunaan alat pelindung diri (APD), kematian gulma serta biaya pengendalian gulma. Data sekunder memuat data terkait letak geografis dan batas wilayah administratif, peta kebun, data iklim meliputi curah hujan, kondisi tanah, luas areal konsesi (HGU), keadaan tanaman produksi, dan biaya pengendalian gulma.

Pengamatan dominasi gulma dilakukan dengan metode analisis vegetasi menggunakan metode kuadran berukuran $50 \mathrm{~cm}$ x $50 \mathrm{~cm}$ pada 12 blok berdasarkan tahun tanam (TT), yaitu TT 1997, TT 1998, TT 1999, TT 2001, TT 2002, TT 2003, TT 2004, TT 2005, 2006, TT 2007, TT 2008, TT 2010, TT 2013. Penga mbilan sampel setiap blok dilakukan dengan teknik "sampling acak tidak langsung" (Tjitrosoedirdjo et al., 1984) di 15 lerengan dan 15 gawangan. Data yang diamatai berupa kerapatan gulma, bobot basah gulma dan frekuensi gulma.

Pengamatan manajemen pengendalian gulma manual meliputi kegiatan perencanaan, pelaksanaan dan evaluasi pengendalian gulma. Perencanaan pengendalian gulma manual melalui survei jenis gulma sasaran pengendalian serta menentukan jenis pekerjaan pengendalian dan kebutuhan tenaga kerja. Pengendalian gulma secara kimia meliputi survei jenis gulma sasaran, kebutuhan tenaga kerja, kebutuhan alat dan bahan serta kalibrasi alat semprot. Data diperoleh melalui wawancara dengan mandor dan asisten serta pengamatan di lapang. Pengamatan kalibrasi alat semprot (nozzel) dilakukan terhadap semua alat semprot yang ada di divisi IV dan 3 tenaga kerja 
sebanyak 5 kali ulangan. Data yang dikumpulkan adalah lebar semprot (meter), kecepatan jalan operator selama 10 detik (meter menit ${ }^{-1}$ ), output semprotatau flow rate di gelas ukur selama 1 menit $\left(\right.$ menit ${ }^{-1}$ ) dan menghitung jumlah volume semprot $\mathrm{ha}^{-1}$ (liter).

Pelaksanaan pengendalian gulma meliputi pengamatan terhadap 5 prinsip tepat pengendalian gulma, yaitu tepat jenis, tepat sasaran, tepat dosis, tepat cara dan tepat waktu, prestasi tenaga kerja dan alat pelindung diri (APD). Pengukuran tepat jenis dan sasaran dilakukan dengan mencatat jenis herbisida dan gulma sasaran pengendalian hasil survei kerapatan gulma oleh mandor harian. Pengukuran tepat dosis dilakukan melalui time mottion studi (TMS) dengan mencatat jumlah dosisi herbisida cap ${ }^{-1}$ dan jumlah cup ha ${ }^{-1}$ yang dibutuhkan saat penyemprotan di lapangan pada 3 tenaga kerja semprot. Pengamatan tepat cara dilakukan dengan mengamati jenis formulasi herbisida yang digunakan saat pengendalian dan mengamati cra kerja metode penegndalian. Pengamatan tepat waktu di lakukan dengam mengamati waktu pengaplikasian herbisida berdasarkan jenis gulma dan kondisi cuaca. Pengamatan prestasi tenaga kerja dilakukan dengan menghitung total luasan pengendalian yang dihasilkan dan dibagikan dengan total tenaga kerja yang digunakan. Jumlah pekerja yang diamati sebanyak 5 orang yang dipilih secara acak sebanyak 5 ulangan.

Evaluasi pengendalian gulma dilakukan pengamatan terhadap mutu semprot dan biaya pengendalian gulma. Mutu semprot dilihat berdasarkan kematian gulma pada blok yang telah disemprot 2 minggu setelah aplikasi (MSA). Biaya pengendalian gulma dihitung berdasarkan penggunaan bahan dan tenaga kerja yang digunakan untuk pengendalian manual dan chemist 5 tahun terakhir.

Data analisis vegetasi diolah untuk mendapatkan angka Nisbah Jumlah Domina (NJD) atau jenis gulma dominan (Sembodo, 2010). Tingkat kesamaan vegetasi gulma setiap blok dibandingkan dengfan menghitung Koefisisen Komunitas (KK). KK dapat dihitung menggunakan indeks kesamaan Bray-Curtis (Ludwig dan Reynolds, 1998). Hitung jarak ketidaksamaan komunitas menggunakan rumus 1-KK. Data jarak ketidaksamaan komunitas diuji dengan analisis cluster metode single linkage untuk mengetahui pengelompokan tahun tanam menggunakan jarak euclidian. Hasil analisis cluster ditampilkan dalam bentuk dendogram. Data lain yang diperoleh diolah menggunakan perhitungan matematis sederhana seperti nilai rata-rata, presentase dan uji kolerasi dengan software Minitab 16 dan Microsoft Excel serta dianalisis secara deskriptif

\section{HASIL DAN PEMBAHASAN}

\section{Nisbah Jumlah Dominan (NJD)}

Analisis vegetasi dilakukan pada tiga belas tahun tanam berbeda yang setiap tahun tanamnya diambil satu field contoh, yaitu 2013 (R13201), 2010 (R10401), 2008 (R08403), 2007 (R07402), 2006 (R06201), 2005 (R05303), 2004 (R04201), 2003 (R03402), 2002 (R02403), 2001 (R01206), 1999 (R99101), 1998 (R98102), 1997 (R97302). Pengambilan data analisis vegetasi berdasarkan tahun tanam ini dikarenakan penutupan kanopi setiap tahun tanam berbeda, sehingga jenis gulma juga berbeda. Tahun tanam dijadikan dasar dalam pengambilan data juga didasarkan dari peraturan perusahaan mengenai intensitas perawatan tanaman. Komunitas gulma dibedakan menjadi gulma di piringan dan gulma di liringan. Pengambilan petak contoh dilakukan sebanyak 15 petak contok di piringan dan 15 petak contoh di liringan untuk setiap field contoh.

Hasil analisis vegetasi gulma di Gurach Batu Estate (GBE) pada piringan (Tabel 1) diperoleh komposisi gulma golongan daun lebar terdiri atas 25 jenis , rumput 3 jenis, paku-pakuan 7 jenis, serta teki 6 jenis. Gulma yang paling dominan pada blok tahun tanam (TT) 2013 adalah Mucuna bracteata dengan NJD 38.79\%, TT 2010 - TT 1997 gulma yang paling dominan adalah dari golongan rumput yaitu Ottocloa nodosa dengan NJD TT 2008 28.86\%, TT $200744.28 \%$, TT $200656.79 \%$, TT 2004 53.09\%, TT 2003 48.48\%, TT 2002 26.96\%, TT $200135.55 \%$, TT $199937.51 \%$, TT 1998 49.09\%, dan TT $199731.46 \%$.

Gulma golongan daun lebar tertinggi terdapat pada tahun 2013 dengan presentase $38.79 \%$. Gulma golongan rumput tertinggi terdapat pada tahun 2006 dengan presentase $56.79 \%$. Gulma golongan paku-pakuan tertinggi terdapat pada tahun 2003 dengan presentase $17.01 \%$. Gumla golongan teki tertinggi terdapat pada tahun 1997 dengan presentasen $8.09 \%$.

Hasil analisis vegetasi gulma pada liringan di GBE yang di tunjukan pada Tabel 2 menunjukan gulma yang paling dominan pada TT 2013 adalah Ottocloa nodosa dengan NJD 40.81\%, TT 2010 adalah Mucuna bracteata dengan 


\begin{tabular}{|c|c|c|c|c|c|c|c|c|c|c|c|c|c|c|}
\hline \multirow{2}{*}{ No } & \multirow{2}{*}{ Jenis Gulma } & \multicolumn{13}{|c|}{ NJD per Tahun Tanam (\%) } \\
\hline & & 2013 & 2010 & 2008 & 2007 & 2006 & 2005 & 2004 & 2003 & 2002 & 2001 & 1999 & 1998 & 1997 \\
\hline & Daun Lebar & & & & & & & & & & & & & \\
\hline 1 & Ageratum conyzoides & & & & 2.07 & 1.20 & 2.65 & 1.08 & & 1.85 & 2.68 & 0.92 & & \\
\hline 2 & Asystasia intrusa & & 4.84 & 1.16 & 8.80 & 3.75 & 9.28 & & 4.67 & 1.25 & 2.28 & 1.25 & 0.73 & \\
\hline 3 & Borreria alata & & 2.03 & 8.96 & 5.94 & 8.66 & 13.21 & 2.70 & 2.05 & 9.75 & 9.49 & 13.50 & 1.80 & 2.83 \\
\hline 4 & Centella asiatica & & & & & & & & & & & 1.04 & & \\
\hline 5 & $\begin{array}{l}\text { Centrosema } \\
\text { pubescens }\end{array}$ & & 4.22 & 5.98 & & 5.79 & & 7.90 & & 1.53 & 1.84 & & 0.75 & 6.04 \\
\hline \multirow{2}{*}{6} & Cleome & & & & & & & & & & & & & \\
\hline & rutidosperma & & & 3.82 & & 3.21 & & 1.23 & & & 0.75 & & & \\
\hline 7 & Clidemia hirta & & & 2.96 & & & & & & & & & 2.11 & \\
\hline 8 & Dioscorea hispida & & & & & & 1.92 & & & & & 0.99 & & \\
\hline 9 & Euphorbia hirta & & & 1.35 & & & & & & & & & & \\
\hline 10 & Hevea brasiliensis & & & & & & & 1.05 & & & & & & 0.96 \\
\hline \multirow{2}{*}{11} & Melastoma & & & & & & & & & & & & & \\
\hline & malabatricum L. & & & & & & & & & & & 3.06 & 1.84 & 1.32 \\
\hline 12 & Mimosa indica & & & & & & & & & & 1.96 & & & \\
\hline 13 & Mikania micrantha & & 6.52 & & & & & & & & & & 4.32 & 4.25 \\
\hline \multirow{2}{*}{14} & Momordica & & & & & & & & & & & & & \\
\hline & balsamina & & & 0.88 & & & & & & 0.70 & 0.87 & & & \\
\hline 15 & Muccuna Bracteata & 38.79 & 3.43 & 5.49 & & & & & 0.92 & & 6.68 & & & \\
\hline 16 & Oxalis baerrelieri & & & & 1.10 & & & & 0.93 & 1.74 & 2.45 & & 2.23 & \\
\hline 17 & Peperomia pellucida & & 2.73 & 6.60 & 13.67 & 13.48 & 7.85 & 6.18 & 8.67 & 2.93 & 1.61 & & 1.46 & \\
\hline 18 & Phyllanthus niruri & & & 0.83 & 1.95 & 2.43 & & & & 2.94 & & & 0.76 & \\
\hline 19 & Pueraria javanica & & & 1.96 & & & & & 2.13 & 4.64 & & & 2.40 & \\
\hline 20 & $\begin{array}{l}\text { Toxicodendron } \\
\text { radicans }\end{array}$ & & & & & & & & & & & & & \\
\hline 21 & Urena lobata & & 1.42 & & & & & & & 0.82 & & 1.33 & 0.82 & \\
\hline 22 & Mint-mintan & & & 5.81 & & & & 2.55 & 1.29 & & & & & \\
\hline 23 & bunga ungu & & & 1.15 & & & & & 1.21 & 1.84 & 1.63 & 1.30 & & 1.15 \\
\hline 24 & Melastoma rambat & & & & & & & 4.69 & & & & & & \\
\hline \multirow[t]{3}{*}{25} & Sembung & & & & & & & & & & 7.21 & & & \\
\hline & SUB TOTAL & 38.79 & 25.19 & 46.93 & 33.53 & 38.52 & 34.91 & 27.37 & 21.88 & 29.97 & 39.47 & 23.39 & 19.21 & 16.54 \\
\hline & Rumput & & & & & & & & & & & & & \\
\hline 1 & Axonopus compresus & & & & 8.04 & & & 1.09 & & & & & 11.10 & 3.13 \\
\hline 2 & Ottocloa nodosa & 38.27 & 32.64 & 28.86 & 44.28 & 56.79 & 52.79 & 53.09 & 48.48 & 26.96 & 35.55 & 37.51 & 49.09 & 31.46 \\
\hline \multirow[t]{3}{*}{3} & $\begin{array}{l}\text { Paspalun } \\
\text { cuniugatum }\end{array}$ & & 327 & & & 154 & & & 150 & 25.41 & 1485 & 2525 & & 1853 \\
\hline & $\begin{array}{l}\text { cunjugatum } \\
\text { SUB TOTAL }\end{array}$ & $\begin{array}{l}22.93 \\
61.21\end{array}$ & $\begin{array}{r}3.21 \\
35.91\end{array}$ & 28.86 & 52.31 & $\begin{array}{r}1.54 \\
58.33\end{array}$ & 52.79 & 54.18 & $\begin{array}{r}1.59 \\
50.07\end{array}$ & $\begin{array}{l}25.41 \\
52.37\end{array}$ & $\begin{array}{l}14.85 \\
50.39\end{array}$ & $\begin{array}{l}25.25 \\
62.77\end{array}$ & 60.20 & $\begin{array}{l}18.53 \\
53.13\end{array}$ \\
\hline & Paku-pakuan & & & & & & & & & & & & & \\
\hline 1 & Adiantum raddianum & & 2.51 & & & & & & & & & & & 1.10 \\
\hline 2 & Cyclosorus aridus & & 2.25 & & & & 1.85 & 1.08 & & & & & & 1.20 \\
\hline 3 & Diplazium asperum & & 12.49 & & 6.94 & & 7.95 & 7.18 & 17.01 & & & & 7.69 & \\
\hline 4 & Nephrolevis biserata & & 15.86 & 11.30 & & & 2.50 & 6.42 & 2.95 & 1.68 & & 3.34 & 9.50 & 3.12 \\
\hline 5 & Pteris vittata & & & & & & & & 0.99 & & & & & \\
\hline 6 & Selaginella & & & & & & & & & & & & & \\
\hline 6 & deoderleinii Hieron & & & & & & & & 4.91 & & & & & 14.02 \\
\hline \multirow[t]{3}{*}{7} & $\begin{array}{l}\text { Stenochlaena } \\
\text { palustris Bedd. }\end{array}$ & & & 8.24 & & & & & & & & & & \\
\hline & SUB TOTAL & 0.00 & 33.10 & 19.54 & 6.94 & 0.00 & 12.30 & 14.68 & 25.85 & 1.68 & 0.00 & 3.34 & 17.20 & 19.45 \\
\hline & Teki & & & & & & & & & & & & & \\
\hline 1 & Cyclosorus aridus & & & & & 1.07 & & & & & & & & \\
\hline 2 & Cyperus cyperoides & & & & & & & 1.12 & & & & & & \\
\hline 3 & Cyperus iria & & & & & & & & 1.07 & & & & & \\
\hline 4 & Cyperus killingia & & 4.22 & 4.67 & 7.22 & 2.08 & & 1.58 & 1.13 & 7.77 & 7.42 & 6.89 & 3.40 & 1.93 \\
\hline 5 & Cyperus rotundus & & 1.58 & & & & & & & 1.31 & 2.72 & 0.99 & & 0.86 \\
\hline \multirow[t]{2}{*}{6} & Scleria sumatrensis & & & & & & & 1.07 & & 6.90 & & 2.61 & & 8.09 \\
\hline & SUB TOTAL & 0.00 & 5.80 & 4.67 & 7.22 & 3.15 & 0.00 & 3.77 & 2.20 & 15.98 & 10.14 & 10.50 & 3.40 & 10.88 \\
\hline
\end{tabular}

Sumber: Pengamatan Penulis

NJD 60.69\%, TT2008, 2007, dan 2006 adalah Ottocloa nodosa dengan NJD 30.56\%, 42.08\%, dan $68.62 \%$, TT 2005 adalah Diplazium asperum dengan NJD 32.14\%, TT 2004, TT 2003, dan TT 2002 adalah Ottocloa nodosa dengan NJD 35,97\% , 47,41\% dan 51.01\%, TT 2002 adalah Selaginella deoderleinii Hieron dengan NJD 25.91\%, TT 1999 adalah Ottocloa nodosa dengan NJD 35.74, TT 1998 adalah Nephrolevis biserata dengan NJD 38.34\%, dan TT 1997 adalah Ottocloa nodosa dengan NJD 27.97\%.
Gulma golongan daun lebar tertinggi terdapat pada liringan TT 2010 dengan presentase $60.69 \%$. Gulma golongan rumput tertinggi terdapat pada liringan TT 2006 dengan presentasi 68,62\%. Gulma golongan paku-pakuan tertinggi terdapat pada liringan TT 1998 dengan presentase $38.34 \%$. Gulma golongan teki tertinggi terdapat pada TT 2002 dengan presentase $6.44 \%$. Golongan gulma yang paling dominan dari 13 blok pengamatan analisis vegetasi di liringan maupun di gawangan termasuk kedalam golongan gulma rumput. 
Tabel 2. Nisbah jumlah dominan liringan

\begin{tabular}{|c|c|c|c|c|c|c|c|c|c|c|c|c|c|c|}
\hline \multirow{2}{*}{ No } & \multirow{2}{*}{ Jenis Gulma } & \multicolumn{13}{|c|}{ NJD per Tahun Tanam (\%) } \\
\hline & & 2013 & 2010 & 2008 & 2007 & 2006 & 2005 & 2004 & 2003 & 2002 & 2001 & 1999 & 1998 & 1997 \\
\hline & Daun Lebar & & & & & & & & & & & & & \\
\hline 1 & Ageratum conyzoides & 0.96 & & & 1.01 & 1.19 & & & & & & 1.35 & & 0.63 \\
\hline 2 & Amorpopalus sp & & & & & & & & & & 1.21 & 2.98 & 1.76 & \\
\hline 3 & Asystasia intrusa & & 15.62 & & 3.88 & 5.57 & 3.03 & & 3.28 & 1.65 & 1.68 & & & \\
\hline 4 & Borreria alata & 3.34 & 1.37 & 2.09 & 5.51 & 7.39 & 16.44 & 4.21 & 1.74 & 1.12 & & 1.38 & & 0.59 \\
\hline 5 & Borreria latifolia & 2.06 & & & & & 1.01 & & & & & & & \\
\hline 6 & Caladium bicolor & & & & 0.87 & & & & & & & & & \\
\hline 7 & Centrosema pubescen & & 1.35 & 2.66 & & & & 6.01 & 0.98 & 0.77 & & 1.82 & 0.74 & 0.61 \\
\hline 8 & Clidemia hirta & & & 5.46 & & & & & & 3.04 & & 4.53 & & \\
\hline 9 & Dioscorea hispida & & & & & & & & & & & & & 1.21 \\
\hline 10 & Euphorbia hirta & & & 1.03 & & & & & & & & & & \\
\hline 11 & Havea brasiliensis & & & 3.32 & 1.70 & & & & 0.75 & & 4.89 & 1.78 & 2.36 & 2.08 \\
\hline 12 & Melastoma & & & & & & & & & & & & & \\
\hline 13 & $\begin{array}{l}\text { malabatricum L. } \\
\text { Mikania micrantha }\end{array}$ & & 886 & & & & & $\begin{array}{l}3.43 \\
2.76\end{array}$ & & 3.10 & & 1.94 & & 0.93 \\
\hline 14 & Mimosa pudica & & & & & & & & & & & 0.74 & & \\
\hline 15 & Momordica balsamina & & & & & & & & 1.79 & & & & & \\
\hline 16 & Mиссипа Bracteata & 36.82 & 60.69 & 3.46 & 11.75 & & 8.29 & & & & 1.11 & 0.73 & & \\
\hline 17 & Peperomia pellucida & & & & 5.26 & & & 0.86 & & & & & & 0.61 \\
\hline 18 & Pueraria javanica & & & 0.74 & 1.13 & & 1.25 & 0.97 & 1.99 & 2.98 & 2.25 & & & \\
\hline 19 & Urena lobata & & & & 5.72 & & 1.69 & & & & & 0.77 & & 0.62 \\
\hline 20 & Bunga ungu & 0.95 & & & & & & & & & 1.07 & 0.71 & & \\
\hline \multirow[t]{3}{*}{21} & Melastoma rambat & & & & & & & 0.84 & & & & & & \\
\hline & SUB TOTAL & 44.13 & 87.89 & 18.76 & 36.83 & 14.15 & 31.70 & 19.08 & 10.53 & 12.66 & 12.22 & 18.72 & 4.85 & 7.28 \\
\hline & Rumput & & & & & & & & & & & & & \\
\hline 22 & Axonopus compresus & & & & 3.43 & & 2.07 & & & & & & & \\
\hline 23 & Brachiara muticha & & & & & & & & & & & & & \\
\hline 23 & (Forsk). Stapl & & & & & & & & & & & & 2.91 & \\
\hline 24 & Cyrtocoocum acresens & & & & & & & 1.83 & & & & & & \\
\hline 25 & Ottocloa nodosa & 40.81 & 12.11 & 30.56 & 42.08 & 68.62 & 37.69 & 27.92 & 35.97 & 47.41 & 17.67 & 35.74 & 24.78 & 27.97 \\
\hline 26 & Paspalum comersonii & & & & & & & & & & & & 0.72 & 0.60 \\
\hline \multirow[t]{2}{*}{27} & Paspalun cunjugatum & 10.84 & & & & & & & & 3.59 & & 0.70 & & \\
\hline & SUB TOTAL & 51.65 & 12.11 & 30.56 & 45.51 & 68.62 & 39.76 & 29.76 & 35.97 & 51.01 & 17.67 & 36.44 & 28.42 & 28.57 \\
\hline & Paku-pakuan & & & & & & & & & & & & & \\
\hline 28 & Adiantum raddianum & & & 1.17 & & & 1.07 & & 1.70 & 6.91 & 3.75 & 6.39 & 1.77 & 6.56 \\
\hline 29 & Cyclosorus aridus & & & & & & & & & & & & & \\
\hline 29 & (Don) Ching. & & & 1.17 & 4.34 & & & & 1.77 & & 3.35 & & 6.41 & 6.60 \\
\hline 30 & Dicranopteris $s p$ & & & 3.88 & & 3.26 & & & 1.45 & 0.81 & & & & \\
\hline 31 & Diplazium asperum & 2.00 & & 11.88 & 10.52 & 13.97 & 13.28 & 32.14 & 23.77 & 9.74 & 6.95 & 7.07 & 15.99 & 11.26 \\
\hline 32 & Gleichenia linearis & & & & & & & & & 3.50 & & 3.59 & 1.25 & \\
\hline 33 & Nephrolevis biserata & & & 23.60 & & & 11.21 & 18.11 & 19.13 & 8.93 & 18.12 & 10.86 & 38.34 & 14.31 \\
\hline 34 & Pteris vittata & & & & & & & & & & & & & 5.69 \\
\hline 35 & Selaginella & & & & & & & & & & & & & \\
\hline 35 & deoderleinii Hieron & & & 1.96 & & & 0.99 & & & & 25.51 & 9.30 & & 10.40 \\
\hline 36 & Stenochlaena palustris & & & 7.03 & & & & & 2.09 & & & & 0.84 & 2.45 \\
\hline 37 & Taenitis blechnoides & & & & & & & & & & & & & 1.31 \\
\hline 38 & Tectania incisa & & & & & & & & & & & & & 4.73 \\
\hline 39 & pakis kelabang & & & & & & & 0.91 & 2.34 & & 3.03 & 0.76 & 2.11 & \\
\hline 40 & pakis keris & & & & & & & & & & & 1.63 & & \\
\hline \multirow[t]{2}{*}{41} & Pakis batang hitam & & & & & & & & & & & 1.97 & & \\
\hline & SUB TOTAL & 2.00 & 0.00 & 50.68 & 14.85 & 17.24 & 26.56 & 51.16 & 52.26 & 29.89 & 60.70 & 41.58 & 66.73 & 63.30 \\
\hline & Teki & & & & & & & & & & & & & \\
\hline 42 & cyperus kyllingia Endl. & & & & 2.81 & & & & 1.24 & & 3.35 & & & \\
\hline \multirow[t]{3}{*}{43} & Scleria sumatrensis & 2.22 & & & & & 1.97 & & & 6.44 & 6.06 & 3.26 & & 0.85 \\
\hline & SUB TOTAL & 2.22 & 0.00 & 0.00 & 2.81 & 0.00 & 1.97 & 0.00 & 1.24 & 6.44 & 9.41 & 3.26 & 0.00 & 0.85 \\
\hline & TOTAL & 100 & 100 & 100 & 100 & 100 & 100 & 100 & 100 & 100 & 100 & 100 & 100 & 100 \\
\hline
\end{tabular}

Sumber: Pengamatan Penulis

\section{Koefisien Komunitas (Indeks Keseragaman)}

Koefisien komunitas (KK) digunakan untuk membandingkan dua komunitas gulma dari dua areal yang berbeda. Nilai dari KK akan menetukan kehomogenan areal tersebut, semakintinggi nilai KK maka tingkat kehomogenan akan semakin tinggi juga. Menurut Santosa et al (2009) koifisen komunitas yang nilainya $\geq 70 \%$ vegetasi relatif homogen. Nilai dari KK 13 blok yang telah dilakukan analisis vegetasi dapat di lihat pada Tabel 3 untuk KK piringan dan Tabel 4 untuk kk liringan.

Berdasarkan Tabel 3, gulma di piringan yang homogen adalah 1999 dan 1997, 2003 dan 1998, 2004 dan 1998, 2002 dan 1999, 2002 dan 1999, 2004 dan 2003, 2007 dan 2003, 2007 dan 2004, 2008 dan 2004, 2010 dan 2005. Nilai koifisien 
komunitas tertinggi yang dibandingkan yaitu pada TT 2004 dan 2003 sebesar $77.37 \%$ sedangan nilai koifisien komunitas terendah yaitu pada blok TT 1998 dan 2010 sebesar $2.33 \%$.

Tabel 3. Nilai presentase koifisien komunitas gulma di piringan

\begin{tabular}{cllllllllllll}
\hline Tahun Tanam & 2010 & 2008 & 2007 & 2006 & 2005 & 2004 & 2003 & 2002 & 2001 & 1999 & 1998 & 1997 \\
\hline 2013 & 12.94 & 4.85 & 2.67 & 3.53 & 4.41 & 3.23 & 3.88 & 4.35 & 9.38 & 4.73 & 2.33 & 6.15 \\
2010 & & 62.53 & 53.41 & 37.23 & 70.71 & 65.14 & 40.76 & 44.83 & 64.94 & 48.99 & 51.51 & 55.87 \\
2008 & & & 67.56 & 55.03 & 69.71 & 70.72 & 49.71 & 58.05 & 51.62 & 60.47 & 57.50 & 57.46 \\
2007 & & & & 62.27 & 65.38 & 75.77 & 74.09 & 64.09 & 49.50 & 57.52 & 66.67 & 53.37 \\
2006 & & & & & 49.34 & 56.57 & 66.52 & 48.64 & 33.88 & 44.68 & 59.54 & 41.16 \\
2005 & & & & & & 69.31 & 63.05 & 54.96 & 53.22 & 57.61 & 52.24 & 58.08 \\
2004 & & & & & & & 77.37 & 58.54 & 49.06 & 57.63 & 71.85 & 60.36 \\
2003 & & & & & & & & 54.73 & 43.33 & 51.37 & 75.55 & 54.41 \\
2002 & & & & & & & & & 58.19 & 76.38 & 50.64 & 68.26 \\
2001 & & & & & & & & & & 53.17 & 50.64 & 68.26 \\
1999 & & & & & & & & & & & 63.17 & 74.02 \\
\hline
\end{tabular}

Sumber: Pengamatan di lapang (2015)

Tabel 4. Nilai presentase koifisien komunitas gulma di liringan

\begin{tabular}{cllllllllllll}
\hline Tahun Tanam & 2010 & 2008 & 2007 & 2006 & 2005 & 2004 & 2003 & 2002 & 2001 & 1999 & 1998 & 1997 \\
\hline 2013 & 77.00 & 57.50 & 63.36 & 64.64 & 59.62 & 44.14 & 63.41 & 50.88 & 22.22 & 50.55 & 44.90 & 43.81 \\
2010 & & 65.69 & 73.92 & 70.54 & 67.90 & 49.91 & 71.22 & 48.63 & 26.13 & 52.82 & 52.05 & 45.32 \\
2008 & & & 68.78 & 42.83 & 99.01 & 69.73 & 82.57 & 56.32 & 43.12 & 63.81 & 69.14 & 61.96 \\
2007 & & & & 45.87 & 98.48 & 58.12 & 79.93 & 51.23 & 31.36 & 54.76 & 58.39 & 52.38 \\
2006 & & & & & 63.91 & 33.99 & 53.94 & 71.93 & 14.86 & 65.31 & 34.82 & 59.90 \\
2005 & & & & & & 68.16 & 69.58 & 55.27 & 38.25 & 57.43 & 63.98 & 53.67 \\
2004 & & & & & & & 67.32 & 44.58 & 33.73 & 45.68 & 67.22 & 49.83 \\
2003 & & & & & & & & 67.47 & 34.63 & 71.10 & 64.70 & 69.59 \\
2002 & & & & & & & & & 28.13 & 83.56 & 47.55 & 75.07 \\
2001 & & & & & & & & & & 37.54 & 33.86 & 40.75 \\
1999 & & & & & & & & & & & 49.60 & 81.55 \\
\hline
\end{tabular}

Sumber: Pengamatan di lapang

Tabel 4 menunjukan koifisien komunitas gulma di liringan GBE, dimana blok tahun tanam yang memiliki gulma homogen adalah TT 2010 dengan 2013, 2007, 2006 dan 2003, TT 2003 dengan 2008 dan 2007, TT 2003 dengan 2007 dan 1999, TT 2005 dengan 2007, TT 1997 dengan 1999. Nilai koifisen komunitas tertinggi yang dibandingkan yaitu pada TT 2005 dengan 2008 sebesar $99.01 \%$ sedangkan nilai koifisien komunitas terendah yaitu pada blok TT 2006 dengan 2001 sebesar $14.86 \%$.

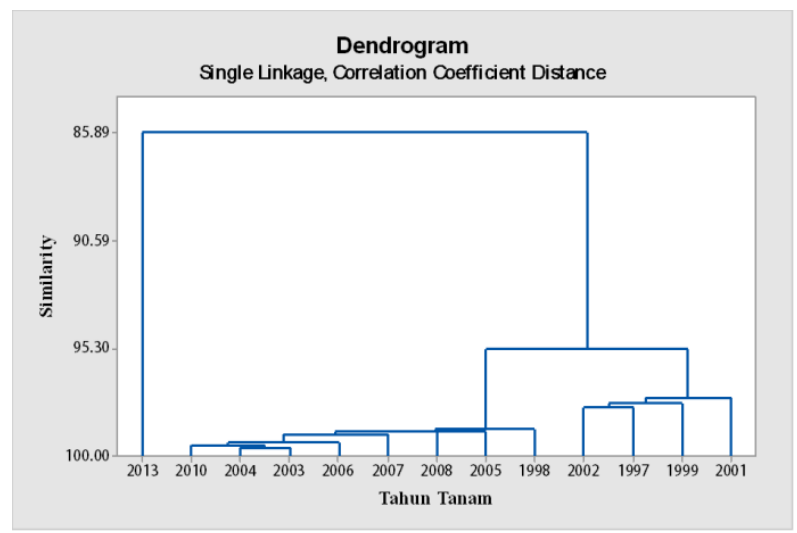

Gambar 1. Dendogram jarak kesamaan tahun tanam berdasarkan hasil analisis gerombol pada piringan

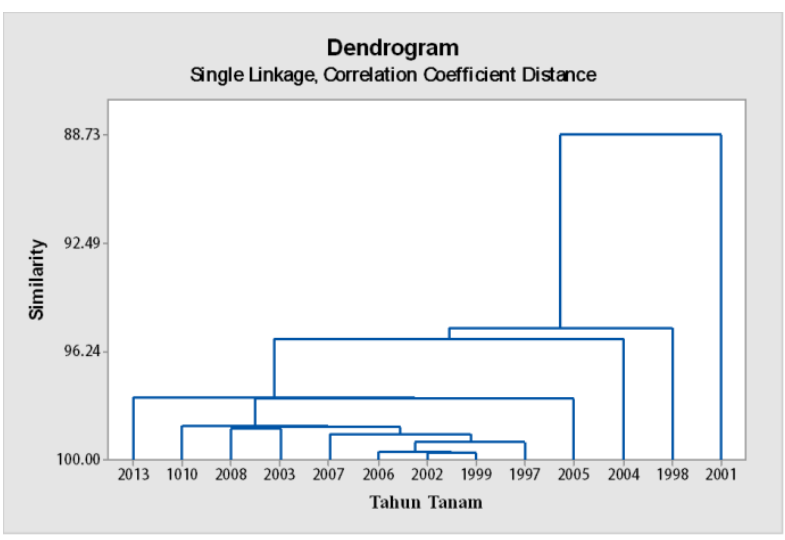

Gambar 2. Dendogram jarak kesamaan tahun tanam berdasarkan hasil analisis gerombol pada piringan

\section{Teknik Pengendalian Gulma}

\section{Pengendalian Gulma Manual}

Pengendalian gulma secara manual di GBE dilakukan dengan cara dongkel anak kayu (DAK), babat, di cabut dan di garuk untuk lompong, micania micrantha, kucingan, tukulan, pakispakisan dan jenis gulma berkayu keras lainnya. Rotasi pengendalian gulma manual dilakukan $2-3$ kali dalam setahuan tergantun kondisi di lapangan. Areal yang menjadi tempat penegndalian gulma secara manual ini yaitu piringan, liringan, patok 
tengah, patok blong, dan di pinggiran sepanjang jalan utama. Pengendalian manual dilakukan apabila kondisi dilapangan sudah tidak memungkinkan untuk dilakukan pengendalian secara kimia, pada kondisi yang sudah menyulitkan kegiatan oprasional dan produksi kebun.

Pengendalian dengan cara DAK difokuskan untuk gulma berkayu (Melastoma, Clidemia) yang dikendalikan dengan cara didongkel hingga ke akar dan di simpan di liringan dengan cara di balik. Alat yang digunakan berupa cangkul. Pengendalian gulma dengan cara di cabut dilakukan pada gulma jenis lompong dan tukulan. Pengendalian gulma dengan cara di babat dilakukan pada liringan tanaman karet yang sudah tua yang areal liringannya di dominasi gulma yang masih bisa di terima (Nephrolepis $s p$ ). Apabila kondisi gulma tersebut sudah mencapai ketinggian $(>45 \mathrm{~cm}$ ) maka dikendalikan dengan cara di babat. Alat yang digunakan adalah parang babat. Pengendalian gulma secara digaruk difokuskan pada aeal kebun entres yang dalam kegiatan pengendaliannya dilarang menggunakan kimia. Kondisi dimana kacangan (Mucuna bracteata) telah menutupi tanaman karet muda (TBM), maka pengendalian gulma manual juga dilakukan dengan cara menurunkan kacangan menggunakan arit.

\section{Pengendalian Gulma Secara Kimiawi}

Herbisida yang biasa di gunakan di GBE ialah herbisida dengan merk dagang Gramoxone 276 SL (bahan aktif parakuat duklorida) untuk herbisisda kontak dan Round Up atau Amiron-M 20 WG (bahan aktif metil mesulfuron) untuk herbisida sistemik. Alat yang digunakan untuk herbisisda jenis kontak yaitu knapsack sprayer SOLO 425 dengan kapasitas 15 L. Jenis nozzle warna merah dan kuning. Alat yang digunakan untuk herbisisda jenis sistemik yaitu micronherbi dengan kapasitas 10 L. Jenis nozzle warna merah dan kuning. Jumlah tenaga kerja harian di GBE DIVISI IV sebanyak 5 orang dengan 1 orang mandor.

Pengecekan kondisi alah khususnya nozzle dilakukan melalui kalibrasi sebelum pelaksanaan dan kalibrasi rutin satu bulan sekali.Hasil kalibrasi nozzle menunjukan nilai rata FR , kecepatan jalan, lebar semprot, dan volume semprot ha $^{-1}$ yang dihasilkan 5 tenaga semprot menggunakan Knapsack sprayer dengan jenis nozzle yang berbeda-beda. Rata-rata FR tertinggi diperoleh penyemprot no 4 dengan nilai sebesar 3 liter menit ${ }^{-1}$. Rata-rata FR dari ke 5 tenaga kerja adalah 1.68 liter menit ${ }^{-1}$. Rata-rata lebar semprot paling tinggi diperoleh penyemprot no 1 dan 5 dengan nilai sebesar 1.35 meter dan rata-rata lebar semprot terendah diperoleh penyemprot no 2 dengan nilai sebesar 1.25 meter. rata-rata lebar semprot dari 5 tenaga kerja adalah 1.32 meter. Rata-rata kecepatan jalan tercepat diperoleh pekerja no 1 dan 4 yaitu 16 meter menit ${ }^{-1}$. Ratarata kecepatn jalan terlambat diperoleh pekerja no 2 yaitu 14 meter menit ${ }^{-1}$. Rata-rat kecepatan jalan dari ke 5 tenaga semprot adalah 15.2 meter menit $^{-}$ ${ }^{1}$. Rata-rata volume semprot tertinggi diperoleh penyemprot no 4 dengan nilai 1422.31 liter ha ${ }^{-1}$. Rata-rata volume semprot terendah diperoleh pekerja no 1 dengan nilai 648.15 liter ha $^{-1}$. Ratarata volume semprot dari ke 5 tenaga kerja adalah 834.41 liter $\mathrm{ha}^{-1}$. Hasil kalibrasi (Tabel 5) menunjukan semua nozzle yang ada di divisi IV tidak sesuai standar perusahaan. Standar flow rate knapsack sprayer untuk nozzle warna merah GBE adalah $450-650 \mathrm{ml} \mathrm{menit}^{-1}$. Flow rate yang tidak sesuai standar ini dikarenakan banyak tenaga kerja yang melakukan kecurangan dengan cara menusuk lobang nozzle agar debit air yang keluar semakin besar dan larutan herbisida segera habis.

Tabel 5. Data kalibrasi Nozzle dan volume semprot larutan ha- ${ }^{-1}$ tim GBE DIVISI IV

\begin{tabular}{|c|c|c|c|c|}
\hline $\begin{array}{l}\text { No } \\
\text { Tangki }\end{array}$ & $\begin{array}{l}\text { Flowrate } \\
\left(\text { L menit }^{-1}\right)\end{array}$ & Swath & $\begin{array}{l}\text { Kecepatan } \\
\text { Jalan } \\
\left(\begin{array}{c}\text { m menit } \\
1 \\
1\end{array}\right)\end{array}$ & $\begin{array}{c}\text { Volume } \\
\text { Semprot } \\
\left(\mathrm{L} \mathrm{ha}^{-1}\right)\end{array}$ \\
\hline \multicolumn{5}{|l|}{ Merah } \\
\hline 1 & 1.4 & 1.35 & 16 & 648.15 \\
\hline 2 & 1.4 & 1.34 & 14 & 746.27 \\
\hline 3 & 1.3 & 1.25 & 15 & 693.33 \\
\hline 4 & 3 & 1.30 & 16 & 1442.31 \\
\hline 5 & 1.3 & 1.35 & 15 & 641.98 \\
\hline Rata-rata & 1.68 & 1.318 & 15.2 & 834.41 \\
\hline
\end{tabular}

Keterangan : Pengamtan di lapang (2015)

\section{Pelaksanaan Pengendalian Gulma}

\section{Efektifitas}

Efektifitas pengendalian gulma berhubungan dengan seberapa besar output karyawan dan kematian gulma. Pengendalian manual dan kimia sama-sama efektif dal hal mematikan gulma, hanya saja waktu yang diperlukan untuk mematikan gulma yang berbeda. Teknik pengendalian gulma secara manual tingkat kematian gulma dapat dilihat serta langsung pada hari itu juga. Pengendalian gulma secara kimia hasil tidak dapat dilihat secara langsung. Proses kematian gulma pada kematian secara kimia dapat dilihat pada Tabel 6.

Tabel 6. Persentase kematian gulma

\begin{tabular}{|c|c|c|c|c|c|}
\hline \multirow[t]{2}{*}{ Pengamatan } & \multirow[t]{2}{*}{ Field } & \multicolumn{4}{|c|}{$\begin{array}{c}\text { Persentase Gejala Kerusakan } \\
(\%)\end{array}$} \\
\hline & & $\mathrm{A}$ & $\mathrm{B}$ & $\mathrm{C}$ & $\mathrm{D}$ \\
\hline 1 & R02402 (A) & 0 & 11.11 & 55.56 & 88.89 \\
\hline 2 & R02402 (B) & 0 & 33.33 & 88.89 & 100 \\
\hline 3 & R02402 (C) & 0 & 22.22 & 44.44 & 88.89 \\
\hline
\end{tabular}

Keterangan: HAS (Haris Setelah Antesis); Sumber: Pengamatan di lapang (2015) 
Jenis herbisida yang digunakan ditrentukan berdasarakan jenis gulma sasaran pengendalian. Jenis gulma di GBE beragam dan didominasi oleh gulma golongan rumput daun lebar, dan pakupakuan.

\section{KESIMPULAN}

Pengendalian gulma di GBE dilakukan dengan tiga metode, yaitu pengendalian secara manual, kimiawi dan kultur teknis. Pengendalian gulma manual diantaranya adalah garuk liringan, dongkel anak kayu, babat gawangan, dan menurunkan kacangan. Pengendalian gulma secara kimiawi diantaranya strip spraying liringan, spot spraying kayu anak, blanket, pengendalian lalang dan kacangan. Pengendalian secara kultur teknis dilakukan dengan menanam Mucuna bracteata.

Berdasarkan hasil analisi vegetasi, gulma yang paling dominan pada tanaman TBM adalah gulma berdaun lebar yaitu Muccuna bracteata dengan NJD 22.8\%. Gulma yang paling dominan pada TM young, TM prime, dan TM old adalah dari jenis rumput yaitu Ottocloa nodosa dengan NJD masing-masing secara berturut-turut $51.2 \%, 41.4 \%$, $46.2 \%$. Setiap komunitas yang dibandingkan memiliki vegetasi gulma yang tidak homogen.

\section{DAFTAR PUSTAKA}

[BPS] Badan Pusat Statistik. 2012. Statistik Karet Indonesia 2011. BPS. Jakarta.

Damanik, S., M. Syakir, M. Tasma, Siswanto. 2010. Budidaya dan Pasca Panen Karet. Pusat Penelitian dan Pengembangan Perkebunan. Bogor.

[FAO] Food Agriculture Organisation. 2012. FAO Statistic. FAO. http://faostat.fao.org/site/567/ DesktopDefault.aspx?PageID=567\#ancor. [29 Januari 2015].

[FAO] Food agriculture organization. 2014. FAOSTAT. FAO. http://faostat3.fao.org/ browse/Q/QC/E. [1 November 2014]

Ludwig, J.A., J.F. Reynold. 1998. Statistic Ecology: A Primer on Methods and Computing. John Wiley \& Sons Inc. New York.

Sembodo, D.R.J. 2010. Gulma dan Pengelolaannya. Graha Ilmu. Yogyakarta.

Setiawan H.D., A. Andoko. 2005. Petunjuk Lengkap Budidaya Karet. PT Agromedia Pustaka. Solo.

Tjitrosoedirdjo, S., I.H. Utomo, J. Wiroatmodjo. 1984. Pengelolaan Gulma di Perkebunan. PT. Gramedia. Jakarta. 